\title{
Metabolic Abnormalities in Colorectal Cancer Patients
}

\author{
Ewa Nowakowska-Zajdel ${ }^{\mathrm{a}}$, Olga Wierzchowiec ${ }^{\mathrm{b}}$, Teresa Kokot ${ }^{\mathrm{a}}$, \\ Edyta Fatygaa, Malgorzata Muc-Wierzgon ${ }^{\mathrm{a}, \mathrm{c}}$
}

\begin{abstract}
Background: The aim of the study was to estimate of the association between the anthropometric obesity, fasting serum concentration of glucose, glycosylated hemoglobin, insulin, total cholesterol, HDL/LDL fractions, triglycerides, a homeostasis model of assessment (HOMA-IR) and percent of HOMA beta-cell function (HOMA- $\beta \%$ ) in non-obese and obese colorectal cancer patients.
\end{abstract}

Methods: The study comprised a total of 300 adult patients (171 men and 129 women) with various stages of colorectal adenocarcinoma. The HOMA-IR and HOMA- $\beta \%$ indexes and fasting serum concentrations of glucose, glycosylated hemoglobin, insulin, total cholesterol, HDL/LDL fractions, triglycerides were determined. According waist circumference values, the examined subjects were divided into two groups: group A (waist circumference $<94 \mathrm{~cm}$ for men and $<80 \mathrm{~cm}$ for women) and B (waist circumference $\geq 94 \mathrm{~cm}$ for men and $\geq 80 \mathrm{~cm}$ for women).

Results: The prevalence of overweight or obesity, estimated by circumference measurements, was identified in $58.5 \%$ of the examined subjects (group B). The average fasting serum concentration of biochemical parameters and HOMA-IR index in the group B was statistically significantly higher vs those in the A group $(\mathrm{P}<0.001)$. The HOMA- $\beta \%$ index did not differ statistically in the analyzed groups $(\mathrm{P}<0.05)$.

Conclusions: Majority of colorectal cancer patients have overweight or obesity. They are associated with hyperglycaemia, insulin

Manuscript accepted for publication June 20, 2012

${ }^{\mathrm{a}}$ Department of Internal Diseases, Silesian Medical University, Bytom, Poland

${ }^{\mathrm{b}}$ Institute of Public Health, School of Higher Vocational Education in Nysa, Poland

${ }^{\mathrm{c}}$ Corresponding author: Malgorzata Muc-Wierzgon, Dept. of Internal Diseases, Silesian Medical University, Zeromskiego 7 st. 41-902

Bytom, Poland. Email:mwierzgon@sum.edu.pl

doi:10.4021/jem103w resistance, hyperinsulinemia and worse lipid profile.

Keywords: Colorectal cancer; Waist circumference; Metabolic parameters; Risk factors

\section{Introduction}

With 655,000 deaths worldwide per year, colorectal cancer is the fourth most common form of cancer in the United States and the third leading cause of cancer-related death in the Western World [1]. In Poland colorectal cancer belongs to tumors placed on the second position as far as incidence is concerned regardless the sex. It also constitutes the third cause of death among the oncological patients.

The risk factors include environmental factors (high fat, high hydrocarbon, high calories and low cellulose diet), internal factors (adenocarcinomas, ulcerative colitis, Crohn's disease) and genetic factors (Lynch syndrome I and II, familial polyposis) [2, 3]. Present reports indicate that there is a relation between metabolic disorders like: overweight, obesity, hyperglycemia, diabetes, lack of physical activity, lipid management disorders and the increased incidence of cancer [4-7]. Each of these components may be an independent factor, while the co-occurrence of a few of them increases the cancer disease risk.

Other studies have shown a greater risk of colorectal cancer mortality associated with the presence of metabolic disorders compared to that associated with the individual metabolic components alone [8].

\section{Aim of the research}

The aim of the study was to estimate of the association between the anthropometric obesity (weight, height, waist circumference values), fasting serum concentration of glucose, glycosylated hemoglobin, insulin, total cholesterol, HDL/ LDL fractions, triglycerides, a homeostasis model of assessment (HOMA-IR) and percent of HOMA beta-cell function (HOMA- $\beta \%$ ) in non-obese and obese colorectal cancer patients. 
Table 1. Characteristics of the Patients

\begin{tabular}{ccccccc}
\hline & \multicolumn{2}{c}{ Sex } & & \multicolumn{2}{c}{ TNM stages } \\
Age (years) & F & M & I & II & III & IV \\
\cline { 2 - 6 } & 129 & 171 & 65 & 81 & 112 & 42 \\
\hline $54.2 \pm 8.2$ & $43.0 \%$ & $57.0 \%$ & $21.5 \%$ & $27.0 \%$ & $37.5 \%$ & $14.0 \%$ \\
\hline
\end{tabular}

\section{Subjects and Methods}

\section{Study group}

The study comprised a total of 300 adult patients with colorectal adenocarcinoma, who had subsequently sought for treatment at a selected Surgical Wards of the southern Poland. Patients were consecutively recruited to the study between May 2006 and July 2007.

The analyzed group was composed of 171 men and 129 women aged 45 - 70; the average age was $54.2 \pm 8.2$ years. In this study, 300 men and women were asked to attend a clinic examination at which time they completed a structured interview with a detailed medical history and risk behavior assessment, a physical examination, and laboratory measurements.

Among the subjects, rectal cancer was present most frequently, histopathologically - adenocarcinoma or ulcerative adenocarcinoma. The largest group was the patients with the G2 degree of histopathological malignancy. In 51.5\% patients, the disease has been diagnosed at the III or IV stages of TNM. It results from it (statistically) that about $14 \%\left(\mathrm{IV}^{\circ}\right.$ TNM) have inconsiderable chances for permanent cure and in the remaining $37.5 \%$ ( $\mathrm{III}^{\circ} \mathrm{TNM}$ ) there is a very high probability of tumor spread, despite the simultaneous implementation of standard, combined oncology treatment (Table 1).

Patients with diagnosed chronic endocrine diseases, psychiatric disorders, alcohol consumption, stroke, severe hepatic and renal diseases and others neoplastic processes or genetic defects were excluded from the study.

\section{Methods}

For each patient, the following data were considered: anthropometric measurements (weight, height, waist circumference values), fasting serum concentration of glucose, glycosylated hemoglobin, insulin, total cholesterol, HDL/ LDL fractions, triglycerides. Also, three index: BMI (Body Mass Index; kg/m²) HOMA-IR (Homeostasis Model of Assessment - Insulin Resistance; fasting glucose (mmol/L) $\mathrm{x}$ fasting insulin (mU/L)/22.5) and HOMA- $\beta \%$ (percent of HOMA beta-cell function) have been determined.

Patients were divided into two groups according waist circumference values: group A (waist circumference $<94 \mathrm{~cm}$ for men and $<80 \mathrm{~cm}$ for women) and B (waist circumference $\geq 94 \mathrm{~cm}$ for men and $\geq 80 \mathrm{~cm}$ for women).

The study protocol was approved by the Local Bioethical Committee and informed consent was obtained from all patients.

Statistical analysis was performed using the statistical package STATISTICA (StatSoft, Poland). Shapiro-Wilk test was used to verify whether variable distributions were normal. Student's-t test was applied to compare the data in every group when distribution of the variable in all compared groups was normal or nonparametric. Mann-Whithney U test was used when distributions of the variable was not normal in at least one of the compared groups. P values $<0.05$ were considered as statistically significant.

\section{Results}

There were non statistically significant differences between sex and ages between both of groups of the patients.

The overweight/obesity, estimated by waist circumference measurements was stated in 58.8\% persons (group B), while normal weight was identified in $41.5 \%$ of the examined subjects (group A) - P $<0.001$. The diseases of the cardiovascular system (hypertension and/or ischemic heart disease and/or resolved myocardial infarction and/or resolved cerebral stroke and/or systemic sclerosis and/or cerebrovascular insufficiency) were diagnosed in $41 \%$ patients of the group B vs $27 \%$ of the A group. Diabetes mellitus type 2 was diagnosed in almost $15.5 \%$ patients with overweight and obesity, while its prevalence in those with normative circumference values amounted to $3.5 \%$.

The average fasting serum concentration of glucose, glycosylated hemoglobin, insulin, total cholesterol, HDL/ LDL fractions, triglycerides and HOMA-IR index were statistically significantly higher in overweight/obese subjects 
Table 2. Characteristics Metabolic Parameters in the Analyzed Group

\begin{tabular}{|c|c|c|c|}
\hline & $\begin{array}{l}\text { A group } \\
(\mathrm{n}=129-41.5 \%)\end{array}$ & $\begin{array}{l}\text { B group } \\
(\mathrm{n}=171-58.5 \%)\end{array}$ & $\begin{array}{l}\text { Statistical significance level (U } \\
\text { MannWhitney Test - } \mathrm{P}<0.001)\end{array}$ \\
\hline Diseases of the cardio-vascular system & 35 (27\%) & $70(41 \%)$ & $<0.001$ \\
\hline Diabetes mellitus t.2 & $5(3.5 \%)$ & 27 (15.5\%) & $<0.001$ \\
\hline Glucose (mg\%) & $72(66.0-82.0)$ & $82(76.0 / 93.0)$ & $<0.001$ \\
\hline HBA1c (\%) & $4.6(4.2-4.9)$ & $5.3(4.9-6.1)$ & $<0.001$ \\
\hline Insulin $(\mu \mathrm{IU} / \mathrm{mL})$ & $8.21(6.71-11.9)$ & $13.91(10.01-18.92)$ & $<0.001$ \\
\hline HOMA-IR & $1.83(1.31-5.11)$ & $2.94(2.01-5.94)$ & $<0.001$ \\
\hline НОМА- $\beta$ & $277(131-421)$ & $259.4(149.1-449.2)$ & $<0.01$ \\
\hline Cholesterol (mmol/L) & $5.32 \pm 1.12$ & $6.34 \pm 1.12$ & $<0.001$ \\
\hline $\mathrm{HDL}(\mathrm{mmol} / \mathrm{L})$ & $1.36 \pm 0.38$ & $1.25 \pm 0.13$ & 0.2451 \\
\hline $\mathrm{LDL}(\mathrm{mmol} / \mathrm{L})$ & $3.79 \pm 1.03$ & $4.49 \pm 1.15$ & $<0.001$ \\
\hline Triglycerides (mmol/L) & $0.82(0.72-1.12)$ & 1.37 (0.81 - 1.99) & $<0.001$ \\
\hline
\end{tabular}

when compared to the subjects of A groups $(\mathrm{P}<0.001)$. Overweight/obesity was associated with a 1.5 -fold risk for insulinemia (OR $=1.51 ; 95 \%$ CI: $1.11-1.72 ; \mathrm{P}<0.001)$ and 2-fold risk increase for hypercholesterolemia $(\mathrm{OR}=1.92$; 95\% CI: 1.38 - 2.71; P 0.001). Value of the HOMA-IR > 5 was found in 11 (13\%) patients in the group A and in 39 (22\%) in the group B. Simultaneously, the HOMA- $\beta \%$ index did not differ statistically in this groups $(\mathrm{P}<0.05)$ (Table 2$)$.

\section{Discussion}

Among colorectal cancer patients overweight and obesity are accompanied by multiple metabolic disorders. Obesity and others metabolic disorders constitute a serious socio-economic and medical problem of word and obesity has gained the name of civilization disease of 21st century [9-12]. In etiopathogenesis of colorectal cancer, in the group of the overweight and obese patients, fat tissue is said to be of high importance to processes of neoplastic transformation. Fat tissue is treated like glandular tissue, performing the endocrine, paracrine function, regulating metabolism of triglycerides, influencing the coagulation system or inhibiting antilipolitic effect of insulin [12]. This tissue produces many adipokines, i.e. hormonally active proteins, which play a significant role in the control of systemic metabolic processes (eg. TNF alpha, interleukin 6, TGF beta, IGF1, adiponectin, and others) [12-14]. Another potential mechanism relates to leptin which is tied to obesity and has been shown to stimulate growth of colonic epithelial cells [15].

Glucose homeostasis disorders lead to metabolic changes related to energy consumption, improper secretion of insulin and glucagon, growth hormones and cortisol. Hyperinsulinemia, which accompanies obesity and type 2 diabetes is the risk factor as insulin is simultaneously the tumor growth factor while insulin resistance is of importance in metabolic, hormonal, inflammatory, vascular disorders and cancer diseases [16].

In this study, $58.5 \%$ of the patients were overweight and obese while $15.5 \%$ had already been diagnosed with type 2 diabetes. Published results of meta-analysis of 15 studies covering more than 2.5 million persons confirm that type 2 diabetes is the colorectal cancer risk factor regardless of sex (the relative risk of developing colorectal cancer in diabetics is 1.43) [17]. Other studies prove that the increased colorectal cancer risk is also present in patients with type 1 diabetes and is mainly related to accompanying hyperglycemia. Fasting serum hyperglycemia exceeding $6.1 \mathrm{mmol} / \mathrm{L}$ is 
significantly correlated with the colorectal cancer increased risk $[18,19]$.

In the analyzed overweight and obese patients with colorectal cancer, higher fasting serum concentration of glucose, glycosylated hemoglobin, cholesterol and insulin were observed. The HOMA-IR insulin resistance index was, respectively for the group A and B, 1.83 versus 2.94, with the significant difference in the groups $(\mathrm{P}<0.001)$. HOMA -IR $>5$ was diagnosed in 50 persons (group A and B), which accounts for $16.9 \%$. The results confirm that insulin resistance in combination with obesity may concern even $20-30 \%$ of the population [20].

\section{Conclusions}

1) Majority of colorectal cancer patients have overweight or obesity. 2) They are associated with HOMA-IR index and the higher serum concentration glucose, insulin and worse lipid profile levels.

\section{References}

1. Cancer. National Cancer Institute. USA 2009.

2. Zhang X, Smith-Warner SA, Chan AT, Wu K, Spiegelman D, Fuchs CS, Willett WC, et al. Aspirin use, body mass index, physical activity, plasma C-peptide, and colon cancer risk in US health professionals. Am J Epidemiol. 2011;174(4):459-467.

3. Fernandez E, Gallus S, La Vecchia C, Talamini R, Negri E, Franceschi S. Family history and environmental risk factors for colon cancer. Cancer Epidemiol Biomarkers Prev. 2004;13(4):658-661.

4. Stachowicz M, Mazurek U, Nowakowska-Zajdel E, Niedworok E, Fatyga E, Muc-Wierzgon M. Leptin and its receptors in obese patients with colorectal cancer. J Biol Regul Homeost Agents. 2010;24(3):287-295.

5. Nilsen TI, Vatten LJ. Prospective study of colorectal cancer risk and physical activity, diabetes, blood glucose and BMI: exploring the hyperinsulinaemia hypothesis. Br J Cancer. 2001;84(3):417-422.

6. Cowey S, Hardy RW. The metabolic syndrome: A highrisk state for cancer? Am J Pathol. 2006;169(5):15051522.

7. Zubelewicz-Szkodzinska B, Szkodzinski J, Romanowski W, Blazelonis A, Danikiewicz A, Muc-Wierzgon M, Szkilnik R. Simvastatin decreases concentration of interleukin-2 in hypercholesterolemic patients after treatment for 12 weeks. J Biol Regul Homeost Agents.
2004;18(3-4):295-301.

8. Jaggers JR, Sui X, Hooker SP, LaMonte MJ, Matthews CE, Hand GA, Blair SN. Metabolic syndrome and risk of cancer mortality in men. Eur J Cancer. 2009;45(10):1831-1838.

9. Stepien M, Rosniak-Bak K, Paradowski M, Misztal M, Kujawski K, Banach M, Rysz J. Waist circumference, ghrelin and selected adipose tissue-derived adipokines as predictors of insulin resistance in obese patients: preliminary results. Med Sci Monit. 2011;17(11):PR13-18.

10. Sturmer T, Buring JE, Lee IM, Gaziano JM, Glynn RJ. Metabolic abnormalities and risk for colorectal cancer in the physicians' health study. Cancer Epidemiol Biomarkers Prev. 2006;15(12):2391-2397.

11. Frezza EE, Wachtel MS, Chiriva-Internati M. Influence of obesity on the risk of developing colon cancer. Gut. 2006;55(2):285-291.

12. Gola M. Adiponectin and apM1 polymorphism genes ;overweight/obesity in patients with primery care. Silesian Medical University 2011.

13. Giovannucci E. Metabolic syndrome, hyperinsulinemia, and colon cancer: a review. Am J Clin Nutr. 2007;86(3):s836-842.

14. Muc-Wierzgon M, Nowakowska-Zajdel E, Kokot T, Kozowicz A, Wiczkowski A, Grochowska-Niedworok E, Mazurek U, et al. Genetic disregulation of TNF alpha and TNF alpha type II receptors in colon cancer at the II and III stage of disease. J Biol Regul Homeost Agents. 2006;20(1-2):10-14.

15. Stachowicz M, Mazurek U, Nowakowska-Zajdel E et al: Leptin, obesity and colorectal cancer. Pol.J.Environ. Stud, 2010;19: 225-229

16. Larsson SC, Orsini N, Wolk A. Diabetes mellitus and risk of colorectal cancer: a meta-analysis. J Natl Cancer Inst. 2005;97(22):1679-1687.

17. Jee SH, Ohrr H, Sull JW, Yun JE, Ji M, Samet JM. Fasting serum glucose level and cancer risk in Korean men and women. JAMA. 2005;293(2):194-202.

18. Kominou D, Ayonette A, Richie JP et al: Insulin resistance and its contribution to colon cancerogenesis. Experimental Biology and Medicine, 2008;228: 405-410.

19. Chang CK, Ulrich CM. Hyperinsulinaemia and hyperglycaemia: possible risk factors of colorectal cancer among diabetic patients. Diabetologia. 2003;46(5):595607.

20. Mau nanya dong dok: Mengenal Penyakit Kanker, Jenis, Gejala, Penyebab Berikut Pengobatan Kanker Available at:

https://nanyadongdok.blogspot.com/2017/06/mengenalpenyakit-kangker-jenis-gejala.html 